\title{
The Influence of Plasma Composition in the Thermal Cyclic Performance of Yttria-Stabilized Zirconia (8YSZ) Thermal Barrier Coatings (TBCs)
}

\author{
Bruno Guerreiro ${ }^{1} \cdot$ Rogerio S. Lima ${ }^{1} \cdot$ Nicholas Curry $^{2} \cdot$ Matthias Leitner $^{2} \cdot$ \\ Karl Körner ${ }^{2}$
}

Submitted: 3 September 2020/in revised form: 26 November 2020/ Accepted: 23 December 2020/Published online: 20 January 2021 (C) ASM International 2021

\begin{abstract}
In the combustion chambers of gas turbine engines, $\mathrm{ZrO}_{2}-8 \mathrm{wt} . \% \mathrm{Y}_{2} \mathrm{O}_{3}$ (YSZ) TBCs are commonly applied by air plasma spray (APS) using $\mathrm{Ar}-/ \mathrm{H}_{2}$-based plasmas via legacy torches. Alternatively, $\mathrm{N}_{2} / \mathrm{H}_{2}$ plasmas could be used with the potential of increasing overall deposition efficiency (DE) and hence reduce the consumption of high-value feedstock powder. Also, by increasing DE, spraying time would be reduced, thereby providing another contribution to bring down production costs. In this work, TBCs were prepared with Ar- and $\mathrm{N}_{2}$ based plasmas with different YSZ powders using Metco $9 \mathrm{MB}$ legacy torch. The use of $\mathrm{N}_{2}$-based plasma resulted in higher particle temperature and lower particle velocity values than those provided by the Ar-based plasma. The measured DEs were between 41-43 and 53-60\% for the Arand $\mathrm{N}_{2}$-based plasmas, respectively. This represents a $\sim 40 \%$ increase in the DE. The coatings produced with the
\end{abstract}

This article is an invited paper selected from abstracts submitted for the 2020 International Thermal Spray Conference, ITSC2020, that was to be held from June 10-12, 2020, in Vienna, Austria. The conference was cancelled due to the coronavirus (COVID-19) pandemic. The paper has been expanded from the planned presentation.

\section{Bruno Guerreiro}

bruno.guerreiro@cnrc-nrc.gc.ca

1 National Research Council of Canada, 75 de Mortagne Blvd., Boucherville, QC J4B 6Y4, Canada

2 Treibacher Industrie AG, Auer-von-Welsbach-Straße 1, 9330 Althofen, Austria two different plasmas exhibited equivalent porosity levels $\sim 11-13 \%$. On average, the lowest thermal conductivity values were given by a $\mathrm{N}_{2}$-based LD-B YSZ TBC. In the furnace cycle test, the performance of the TBCs prepared with the $\mathrm{N}_{2}$-based plasma was superior to that of the TBCs prepared with the Ar plasma, and also exceeding that of an industrial APS TBC benchmark.

Keywords APS $\cdot$ Ar- $\mathrm{H}_{2} \cdot$ deposition efficiency (DE) $\cdot \mathrm{N}_{2}-$ $\mathrm{H}_{2} \cdot \mathrm{TBC} \cdot$ thermal conductivity $\cdot$ thermal cycling (FCT) . YSZ

\section{Introduction}

Air plasma spray (APS) is used in the production of $\mathrm{ZrO}_{2^{-}}$ $8 \mathrm{wt} . \% \mathrm{Y}_{2} \mathrm{O}_{3}$ (YSZ) thermal barrier coatings (TBCs) for the combustion chambers of gas turbine engines. TBCs protect the underlying metal part against the heat of combustion and, along with internal cooling, allow for higher operating temperatures with increased engine efficiencies (Ref 1). An APS TBC is composed of the ceramic topcoat, like YSZ and a MCrAlY $(\mathrm{M}=\mathrm{Ni}, \mathrm{Co}$. NiCo or CoNi) bond coat (BC) (Ref 1, 2). In APS, the feedstock powder particles melt when in contact with the high plasma temperatures. A plasma is generated by imposing an electric potential difference between two electrodes in a presence of a gas. Argon (Ar) is typically the primary gas used for the plasma generation, although nitrogen $\left(\mathrm{N}_{2}\right)$ can also be employed as primary. Hydrogen $\left(\mathrm{H}_{2}\right)$ is generally employed as a secondary gas for APS torches, because it increases the thermal conductivity (i.e., thermal efficiency) of the $\mathrm{Ar}$ and $\mathrm{N}_{2}$ primary plasmas. However, it does not significantly affect the fundamental heating and momentum of the primary gas. According to Ingham and Fabel (Ref 3), $\mathrm{N}_{2}$ plasmas in 
general tend to exhibit lower temperatures but higher enthalpy (i.e., heat content) values than those of Ar-based ones. Murphy and Arundell (Ref 4) showed that the thermal conductivity values of $\mathrm{N}_{2}$-based plasmas are higher than those of Ar-based at the peak of their temperatures. Consequently, the use of $\mathrm{N}_{2}$ as a primary gas in plasma has the potential to improve the deposition efficiently (DE) of sprayed particles. In fact, Marple et al. (Ref 5) have demonstrated this effect, showing maximum YSZ DE values of $38 \%$ and $70 \%$ for $\mathrm{Ar} / \mathrm{H}_{2}$ and $\mathrm{N}_{2} / \mathrm{H}_{2}$ plasmas for a legacy 9MB Metco plasma torch, respectively. Moreover, Lima et al. (Ref 6) reported that YSZ TBCs sprayed via the $3 \mathrm{MB}$ Metco legacy APS torch using $\mathrm{N}_{2}$-based plasmas can display (1) twice the DE values, (2) equivalent furnace cycle test (FCT) lifetimes and (3) similar thermal conductivity values as those of Ar-based ones. In the current work, the advantages of using $\mathrm{N}_{2}$ - versus Ar-based plasmas are explored again; this time by spraying TBCs via the 9MB Metco legacy APS torch and two YSZ feedstock powders.

The objective of this additional work is to demonstrate yet again that $\mathrm{N}_{2} / \mathrm{H}_{2}$ plasma YSZ TBCs produced via legacy APS torches can be engineered to exhibit significantly higher deposition efficiency (DE) levels than those of a $\mathrm{Ar} / \mathrm{H}_{2}$ plasmas, while meeting the key performance standards (i.e., thermal conductivity and thermal cycle life) of Ar-based plasma YSZ TBCs.

\section{Experimental Procedure}

\section{Materials}

Two YSZ powders $\left(\mathrm{ZrO}_{2}-8 \mathrm{wt} . \% \mathrm{Y}_{2} \mathrm{O}_{3}\right)$ from Treibacher Industrie AG (Althofen, Austria) were used, namely AuerCoat YSZ LD grade A (lot: 170901-A) and AuerCoat YSZ LD grade B (lot: 170901-B). Both powders are agglomerated and sintered type and were prepared from fine YSZ particles. The two grades display slightly different particle size distributions and the same chemical composition, as shown in Table 1.

\section{TBC Preparation Using $\mathrm{Ar} / \mathrm{H}_{2}$ and $\mathrm{N}_{2} / \mathrm{H}_{2}$ Plasmas}

The BC (150-200 $\mu \mathrm{m})$ was deposited by APS via the 9MB APS torch and NiCoCrAlY+HfSi (Amdry 386-4) feedstock (Oerlikon Metco, Westbury, NY, USA) using a $\mathrm{N}_{2}-$ single plasma (NRC \#181031B2). The BC roughness was $\mathrm{R}_{\mathrm{a}} \sim 10 \mu \mathrm{m}$. The substrates were grit blasted with white alumina grit\#60 prior to the deposition of any coating. Just one set of $\mathrm{BC}$ was employed for all TBCs evaluated in this study.

Both YSZ powders were sprayed via the 9MB legacy APS torch (Oerlikon Metco, Westbury, NY, USA) with Thfree cathodes (2M11-TF). The anodes (nozzles) displayed a thorium-free tungsten lining (GW-TF and GHW-TF, for the $\mathrm{Ar} / \mathrm{H}_{2}$ and $\mathrm{N}_{2} / \mathrm{H}_{2}$ plasmas, respectively). In order to improve the comparability between the TBCs produced by both systems, each plasma (i.e., $\mathrm{Ar} / \mathrm{H}_{2} \& \mathrm{~N}_{2} / \mathrm{H}_{2}$ ) was operated with a respective brand new set of electrodes. The $9 \mathrm{MB}$ front insulator assemblies for the Ar- and $\mathrm{N}_{2}$-based plasmas were the (1) Ar 9MB50 and (2) N 9MB55; respectively. The \#4 powder port (2.44 $\mathrm{mm}$-single feed) was employed to spray both YSZ feedstocks.

The temperature (T) and velocity (V) values of the YSZ particles were measured using the Accuraspray G3C system (Tecnar, St-Bruno, QC, Canada) at the same spray distance used during sample preparation.

For the deposition of the BCs and YSZ topcoats, the substrates were placed on a rotating carrousel fixture, while the torch exhibited a linear horizontal displacement.

The temperature of the YSZ TBCs during deposition was monitored using an infra-red camera. The maximum YSZ surface temperature during spraying was $\sim 200{ }^{\circ} \mathrm{C}$.

YSZ TBCs were prepared using LD-A and LD-B powders for:

(a) FCT evaluation-400-45- $\mu \mathrm{m}$ YSZ topcoat on Hastelloy $X$ puck-shaped substrates $(25.4 \mathrm{~mm}$ diam $\times 6.2 \mathrm{~mm}$ thick) with $\mathrm{BC}$;

(b) Adhesion testing-400-450- $\mu \mathrm{m}$ YSZ topcoat on mild steel puck-shaped substrates $(25.4 \mathrm{~mm}$ diam $\times$ $6.4 \mathrm{~mm}$ thick) with $\mathrm{BC}$;

Table 1 Particle size distributions and compositions for the two grades of AuerCoat YSZ powder (LD-A and LD-B)

\begin{tabular}{|c|c|c|c|c|c|c|c|c|c|c|c|c|}
\hline \multirow[t]{2}{*}{ Powder } & \multicolumn{3}{|c|}{$\begin{array}{c}\text { Size } \\
\text { distribution/ } \\
\mu \mathrm{m}\end{array}$} & \multirow[t]{2}{*}{$\mathrm{ZrO}_{2} / \mathrm{wt} . \%$} & \multirow[t]{2}{*}{$\mathrm{Y}_{2} \mathrm{O}_{3} / \mathrm{wt} . \%$} & \multirow[t]{2}{*}{$\mathrm{HfO} / \mathrm{wt} . \%$} & \multirow[t]{2}{*}{$\mathrm{Al}_{2} \mathrm{O}_{3} / \mathrm{ppm}$} & \multirow[t]{2}{*}{$\mathrm{Fe}_{3} \mathrm{O}_{2} / \mathrm{ppm}$} & \multirow[t]{2}{*}{$\mathrm{SiO}_{2} / \mathrm{ppm}$} & \multirow[t]{2}{*}{$\mathrm{CaO} / \mathrm{ppm}$} & \multirow[t]{2}{*}{$\mathrm{TiO}_{2} / \mathrm{ppm}$} & \multirow[t]{2}{*}{$\mathrm{U}+\mathrm{Th} / \mathrm{ppm}$} \\
\hline & $\overline{d_{10}}$ & $d_{50}$ & $\overline{d_{90}}$ & & & & & & & & & \\
\hline LD-A & 24 & 50 & 87 & Balance & 7.6 & 1.94 & $<50$ & $<50$ & $<100$ & $<500$ & $<500$ & $<10$ \\
\hline LD-B & 33 & 57 & 89 & Balance & 7.6 & 1.94 & $<50$ & $<50$ & $<100$ & $<500$ & $<500$ & $<10$ \\
\hline
\end{tabular}


(c) Metallographic observation-400-450- $\mu \mathrm{m}$ YSZ topcoat on mild steel puck-shaped substrates $(25.4 \mathrm{~mm}$ diam $\times 6.4 \mathrm{~mm}$ thick) with $\mathrm{BC}$;

(d) Thermal diffusivity/thermal conductivity-800-900$\mu \mathrm{m}$ YSZ on Almen N strip substrates without BC.

\section{Microstructural Characterization}

For metallographic observation, samples were initially vacuum impregnated in epoxy resin and then ground and polished following standard metallography procedures. After polishing, samples were observed using a field emission gun scanning electron microscope Hitachi S-4700 (FEG-SEM) in backscattered electron imaging mode (YAGBSE) or an Olympus optical microscope.

\section{Deposition Efficiency}

The deposition efficiency (DE) was calculated having in consideration the weight of the deposit and the amount of powder that was used during spray while the torch was over the Almen strip substrate.

\section{Porosity Measurements}

Evaluation of porosity was performed using image analysis of SEM images taken at $1000 \times$ magnification. The images were then processed by an image analysis routine for the open-source software ImageJ. The processing routine automatically did a threshold on the image to form a binary (black and white image where the porosity is shaded black). After all images were treated, the area of the porosity in each image was calculated as a percentage of the total field of view. The results were then averaged over a minimum of 20 micrographs analyzed. It needs to be stressed that image analysis technique measures the coarse porosity of thermal spray coatings, i.e., pores from $\sim 1 \mu \mathrm{m}$ to $20 \mu \mathrm{m}$ in size. This comes from the fact that pores smaller than $\sim 1 \mu \mathrm{m}$ cannot be sampled via image analysis from pictures taken at $1000 \times$ magnification.

\section{Bond Strength Testing}

Bond strength was measured according to ASTM C633. In ASTM C633, the coating and respective substrate are bonded to loading fixtures using an epoxy glue; the full assembly is then subject to a tensile load that is perpendicular to the plane of the coating. FM1000 epoxy glue (Couch Sales LLC, Hilton Head Island, SC, USA) was used (it requires $1.5 \mathrm{~h}$ at $180{ }^{\circ} \mathrm{C}$ for curing). An Instron 5582 universal testing machine (Burlington, ON, Canada) was used with a dynamic load up to $100 \mathrm{kN}$ at a constant speed of $1.2 \mathrm{~mm} / \mathrm{min}$.

\section{Thermal Conductivity Measurements}

Samples for the thermal conductivity (TC) measurement were first cut into $10 \mathrm{~mm} \times 10 \mathrm{~mm}$ coupons using a precision sectioning saw and detached from the substrate using an acid bath of hydrochloric acid in order to produce free-standing coatings. Initially, the thermal diffusivity $(T D)$ values of the free-standing YSZ TBCs were measured using the Xenon lamp flash technique (HT HyperFlash, Netzsch GmbH, Germany). Four samples from each plasma condition were measured in their as-sprayed state. In each case, the samples were measured from room temperature (RT) up to $1200{ }^{\circ} \mathrm{C}$ in $200^{\circ} \mathrm{C}$ temperature steps. The measurement steps consisted of 5 "shots" performed on each sample at each temperature step to collect a reliable average value of thermal diffusivity. The complete test program requires approximately 7 hours to complete. In addition to the as-sprayed samples, three additional samples were heat-treated for 10 hours at $1200^{\circ} \mathrm{C}$ before being analyzed using the sample thermal diffusivity program. The heat treatment was performed as it is known that the as-sprayed TBC will sinter partially on first exposure to high temperatures. Therefore, a short heat treatment is performed in order to produce a more representative and stable coating structure for measurement.

The specific heat capacity $(C p)$ for the coatings was evaluated using the measurements from the flash technique. In this case, the detected maximum temperature increase $(\Delta T)$ of the sample due to the (Xenon lamp) heat pulse is used to calculate $C p$ for the sample when compared to the $\Delta T$ of a calibrated reference sample measured in the same equipment. The specific heat capacity was evaluated for each measurement 'shot' performed in the evaluation. Average values for specific heat capacity versus temperature were calculated for each set of four coating samples to produce a dataset that was used for later thermal conductivity calculation. It is often assumed that specific heat capacity for YSZ coatings is stable and indeed often literature values of $\mathrm{Cp}$ are used in thermal conductivity evaluations. In reality, the specific heat capacity of the coating changes when exposed to higher temperatures due to structural sintering and changes in the crystal lattice (Ref 7). The approach of calculation specific heat capacity for each set of coatings allows for more accurate final thermal conductivity calculation as variations in specific heat capacity from coating structural variations and thermal exposure states is taken into account.

Finally, the TC values of the YSZ TBCs were calculated using the YSZ TBC density $(d)$ values, the coating specific 
heat $(C p)$ values and the YSZ TBC $T D$ values; i.e., $T C=$ $d \times C p \times T D$. Evaluation of the TC was carried out using Proteus thermal analysis software (Netzsch GmbH, Germany) using model correction for translucent materials.

\section{Thermal Cycle Life: Furnace Cycle Testing (FCT)}

For each spray set, a total of 4 TBC samples were employed during the FCT evaluation. The FCT was performed in open air and consisted of an $1100{ }^{\circ} \mathrm{C}$ furnace hold for $60 \mathrm{~min}$, followed by forced air cooling to $100{ }^{\circ} \mathrm{C}$ within $10 \mathrm{~min}$. All TBC samples were tested in one single batch. The samples were monitored for surface integrity using an automated image capture system of the sample stage on cooling. TBC failure was deemed to have occurred when $20 \%$ of the TBC surface showed spallation.

An industrial reference TBC was also added to the FCT study to serve as a control. The industrial reference TBC was sprayed using another commercial APS torch (F4-MB, Oerlikon Metco, Westbury, NY, USA) via an $\mathrm{Ar} / \mathrm{H}_{2}$ plasma. Both MCrAlY BC and YSZ topcoat were sprayed using the F4-MB APS torch. The reference YSZ feedstock was a conventional, commercially available A\&S powder with a comparable particle size distribution to AuerCoat YSZ LD-A. The industrial reference TBC was sprayed at the powder feed rate of $90 \mathrm{~g} / \mathrm{min}$ and exhibited an average deposition rate of $\sim 10 \mu \mathrm{m} /$ pass (high robot motion speed), with DE ranging from 42 to $44 \%$. Moreover, the industrial reference YSZ ceramic topcoat exhibited thicknesses comparable to those of the 9MB APS torch samples $(\sim 400 \mu \mathrm{m})$. The porosity of the YSZ TBC reference ranged from 15 to $18 \%$.

\section{Results and Discussion}

\section{Powders Characterization}

Two grades of YSZ powder were used, namely LD-A and LD-B, where the latter shows a slightly larger PSD, with $\mathrm{d}_{50}$ of 57 versus $50 \mu \mathrm{m}$ (Table 1). The powders morphology and microstructure are shown in Fig. 1. The two powders are mostly spherical (Fig. 1a and b), displaying internal porosity (Fig. $1 \mathrm{a}^{\prime}$ and $\mathrm{b}^{\prime}$ ).

\section{Sample Preparation}

The deposition parameters employed in this work were defined based on the know-how of the National Research Council of Canada on spraying YSZ TBCs using $\mathrm{Ar} / \mathrm{H}_{2}$ and $\mathrm{N}_{2} / \mathrm{H}_{2}$ plasmas via legacy APS torches (Ref 5,6 ), as well as a quick optimization process (not described in this work). The summary of the spray parameters can be found in
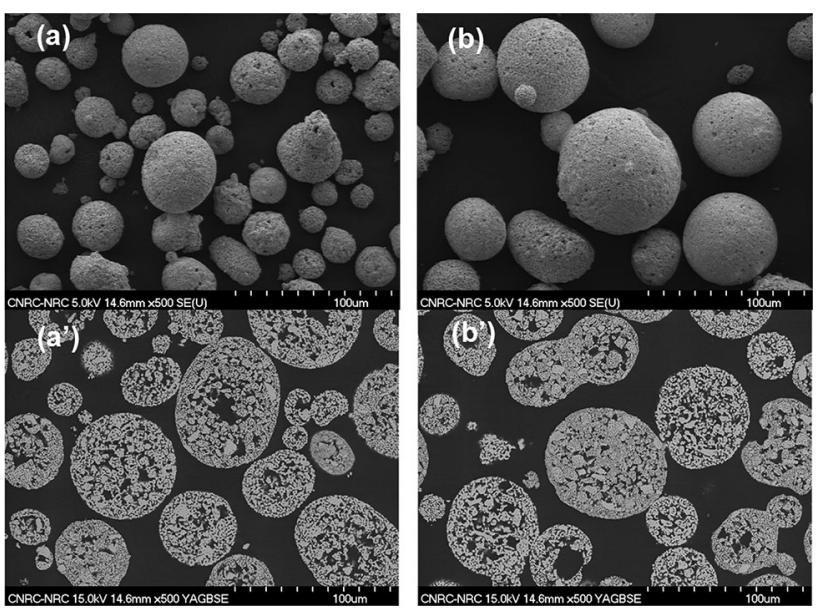

Fig. 1 SEM images of the two different YSZ grade powders displaying their morphology (top row) and microstructure (bottom row): (a) and (a') LD-A; (b) and (b') LD-B

Table 2. Information on particle temperature and velocity, deposition temperature, deposition rate (DR), DE and porosity levels are given in Table 3 . The results of particle $\mathrm{T} \& \mathrm{~V}$ values (Table 3) indicate that $\mathrm{Ar} / \mathrm{H}_{2}$ plasmas yield lower particle $\mathrm{T}$ and higher particle $\mathrm{V}$, whereas $\mathrm{N}_{2} / \mathrm{H}_{2}$ plasmas produce the opposite result. This effect has also been reported by Marple et al. (Ref 5) and Lima et al.(Ref 6), i.e., Ar-based plasmas tend to induce higher particle velocities and lower particle temperatures when compared to $\mathrm{N}_{2}$-based ones (under similar conditions of power, flow and spray distance). Briefly and according to Ingham and Fabel (Ref 3), Ar-based plasmas exhibit higher temperatures than $\mathrm{N}_{2}$ ones, whereas $\mathrm{N}_{2}$-based plasmas exhibit higher enthalpy (heat-content) levels than Ar ones. It needs to be stressed that the velocity of a plasma plume is primarily caused by the rapid volume expansion resulting from the temperature to which the gas is heated by the torch. Consequently, due to their higher temperatures, the velocities of Ar-based plasmas will tend to be higher than those of $\mathrm{N}_{2}$-based ones. As the velocity of the powder particles is proportional to the velocity of the plasma gas (via dragging), $\mathrm{N}_{2}$-based plasma-sprayed particles will tend to exhibit lower velocity levels than those sprayed via Arbased plasmas (under similar conditions of power, flow and spray distance), as shown in Table 2 . As a result, due to a longer dwell time within the plasma plume, the $\mathrm{T}$ values for of the $\mathrm{N}_{2} / \mathrm{H}_{2}$-sprayed particles are higher than those of the $\mathrm{Ar} / \mathrm{H}_{2}$ ones, as also shown in Table 3 (for the same spray distance).

As seen in Table 3, the DE values using the Ar-based plasma were lower than those of the $\mathrm{N}_{2}$-based plasma ( $\sim 42$ versus $\sim 57 \%$ ), despite the fact that the powder feed rate for $\mathrm{N}_{2}$-based sprayed particles was $50 \%$ higher than that employed for the Ar-based one. Consequently, 
Table 2 Summary of the spray parameters employed to spray the LD-A and LD-B YSZ feedstocks. The composition was provided in the powders' certificate of analysis (n.a. not applicable)

\begin{tabular}{|c|c|c|c|c|c|c|c|c|c|}
\hline Set & NRC ID\# & $\begin{array}{c}\text { YSZ } \\
\text { powder }\end{array}$ & $\begin{array}{l}\text { Ar flow } \\
\text { (lpm) }\end{array}$ & $\begin{array}{l}\mathrm{N}_{2} \text { flow } \\
\text { (lpm) }\end{array}$ & $\begin{array}{l}\mathrm{H}_{2} \text { flow } \\
\text { (lpm) }\end{array}$ & $\begin{array}{c}\text { Carrier } \\
(\mathrm{lpm})\end{array}$ & $\begin{array}{c}\mathrm{I} \\
(\mathrm{A})\end{array}$ & $\begin{array}{l}\text { V (V) @ power } \\
\text { supply }\end{array}$ & $\begin{array}{c}\text { Torch } \\
\text { power }(\mathrm{kW})\end{array}$ \\
\hline LD-A $\mathrm{Ar} / \mathrm{H}_{2}$ & 181108B1 & LD-A & 40 & n.a. & 12 & $\begin{array}{c}\mathrm{Ar} \\
@ 6 \mathrm{lpm}\end{array}$ & 625 & 69 & 43 \\
\hline LD-A N $\mathrm{N}_{2} / \mathrm{H}_{2}$ & 181113B1 & LD-A & n.a. & 50 & 10 & $\begin{array}{c}\mathrm{N}_{2} \\
\text { @6 lpm }\end{array}$ & 490 & 84 & 41 \\
\hline LD-B Ar/ $\mathrm{H}_{2}$ & 181114B1 & LD-B & 40 & n.a. & 12 & $\begin{array}{c}\mathrm{Ar} \\
@ 6 \mathrm{lpm}\end{array}$ & 600 & 70 & 42 \\
\hline LD-B N $\mathrm{N}_{2} / \mathrm{H}_{2}$ & 181113B3 & LD-B & n.a. & 50 & 10 & $\begin{array}{c}\mathrm{N}_{2} \\
@ 6 \mathrm{lpm}\end{array}$ & 490 & 84 & 40 \\
\hline
\end{tabular}

Table 3 Torch/sample speed, spray distance (SD), particle temperature and velocity, maximum deposition surface temperature, powder feed rate (PFR), deposition rate (DR), DE and porosity values for the YSZ TBC samples prepared according to the parameters highlighted in Table 2

\begin{tabular}{|c|c|c|c|c|c|c|c|c|c|c|}
\hline Set & $\begin{array}{c}\text { Sample } \\
\text { tangential } \\
\text { speed }(\mathrm{m} / \mathrm{s})\end{array}$ & $\begin{array}{c}\text { Torch } \\
\text { linear speed } \\
(\mathrm{mm} / \mathrm{s})\end{array}$ & $\begin{array}{l}\mathrm{SD} \\
(\mathrm{cm})\end{array}$ & $\begin{array}{c}\text { Part } T_{\mathrm{p}} \\
\quad\left({ }^{\circ} \mathrm{C}\right)\end{array}$ & $\begin{array}{c}\text { Part } V_{\mathrm{p}} \\
(\mathrm{m} / \mathrm{s})\end{array}$ & $\begin{array}{l}\text { Max TBC } \\
\text { temp }\left({ }^{\circ} \mathrm{C}\right)\end{array}$ & $\begin{array}{c}\text { PFR } \\
(\mathrm{g} / \mathrm{min})\end{array}$ & $\begin{array}{c}\mathrm{DR} \\
(\mu \mathrm{m} / \mathrm{pass})\end{array}$ & $\begin{array}{l}\mathrm{DE} \\
(\%)\end{array}$ & $\begin{array}{c}\text { Porosity } \\
(\%)\end{array}$ \\
\hline LD-A Ar/H ${ }_{2}$ & 1.2 & 3 & 12.5 & $\sim 2980$ & $\sim 160$ & $\sim 150$ & 60 & $\sim 27$ & $\sim 41$ & $\sim 11$ \\
\hline LD-A N $\mathrm{N}_{2} / \mathrm{H}_{2}$ & 1.2 & 4 & 12.5 & $\sim 3130$ & $\sim 110$ & $\sim 200$ & 90 & $\sim 39$ & $\sim 53$ & $\sim 12$ \\
\hline LD-B Ar/H & 1.2 & 3 & 12.5 & $\sim 2970$ & $\sim 150$ & $\sim 150$ & 60 & $\sim 27$ & $\sim 43$ & $\sim 13$ \\
\hline LD-B N $\mathrm{N}_{2} / \mathrm{H}_{2}$ & 1.2 & 4 & 12.5 & $\sim 3080$ & $\sim 105$ & $\sim 200$ & 90 & $\sim 43$ & $\sim 60$ & $\sim 12$ \\
\hline
\end{tabular}

this achievement can be thought to be an outstanding feat. In addition, as there are no major differences between the two YSZ powders (LD-A and LD-B) regarding size/composition (Table 1) and morphology (Fig. 1), it can be stated that the differences in DE values are highly linked to the employment of Ar-based or $\mathrm{N}_{2}$-based plasmas.

Porosity levels are all similar for all TBCs (11-13\%). The microstructures of the as-sprayed TBCs are shown in Fig. 2 and 3. The four TBCs display similar microstructure that is typical of porous plasma spray coatings (Ref 2), exhibiting a network of porosity and microcracks, but no through-thickness vertical cracks. Also, there are no major horizontal cracks or gaps between the BCs and YSZ the topcoats, denoting a well-adhered topcoat.

\section{Bond Strength Assessment}

Bond strength tests were performed according to ASTM C633 and are reported in Table 4. There is no significant difference among the $4 \mathrm{TBCs}$, with values in the range 13-15 MPa. No debonding was observed between substrate and BC. In fact, mixed adhesion/cohesion failures occurred
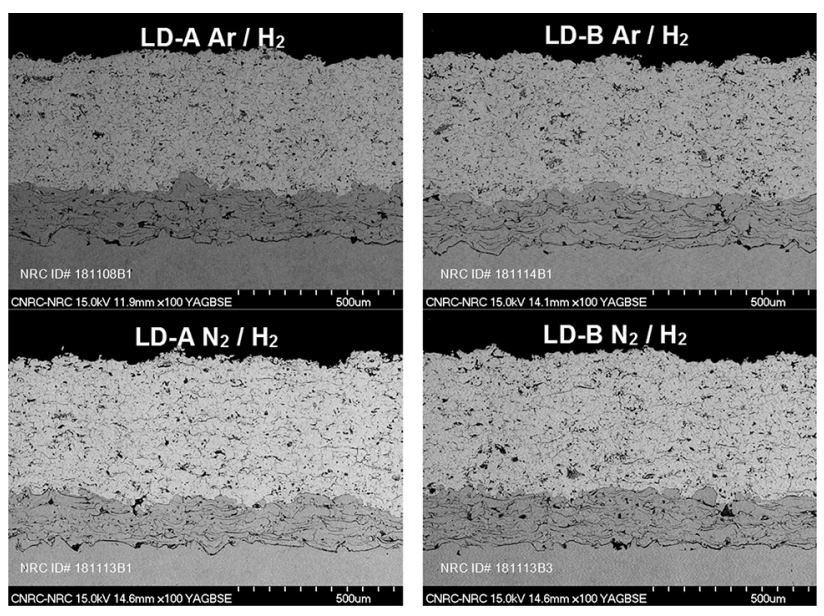

Fig. 2 SEM images $(\times 100$ magnification $)$ of the cross sections of the overall LD-A and LD-B TBC architectures.

between topcoat and bond coat, but mostly within the BC (i.e., cohesive failure). Bond strength is, in general, a function of the different spray parameters, which include among others, particle temperature and velocity values, 
deposition temperature, $\mathrm{BC}$ characteristics, powder features and coating thickness (Ref 8, 9). In this sense, the comparison with literature values is not necessarily fully straightforward. However, Smith et al. (Ref 10) reported the ASTM C633 bond strength values of three distinct series of YSZ APS TBCs. Just like for this work, the FM1000 epoxy glue was also employed. Specifically, "TBC series B" exhibited a $\sim 200-\mu$ m-thick APS NiCrAlY BC and a $\sim 475-\mu$ m-thick APS 7YSZ topcoat at $\sim 10 \%$ porosity (Ref 10 ), which are TBC characteristics and values comparable to the ones employed in this work. Nonetheless, it is important to highlight that the average BC roughness $R_{\mathrm{a}}$ value reported by Smith et al. (Ref 10) was $\sim 9 \mu \mathrm{m}$, whereas that of this project was $\sim 5 \mu \mathrm{m}$. The 3 TBCs samples of "series B" exhibited bond strength values in the range of $\sim 10-12 \mathrm{MPa}$ (Ref 10), i.e., similar to the ones reported in this manuscript. For this reason, it is considered that the bond strength values reported in this work (Table 4) are representative of APS YSZ TBCs that exhibit resembling architectures.
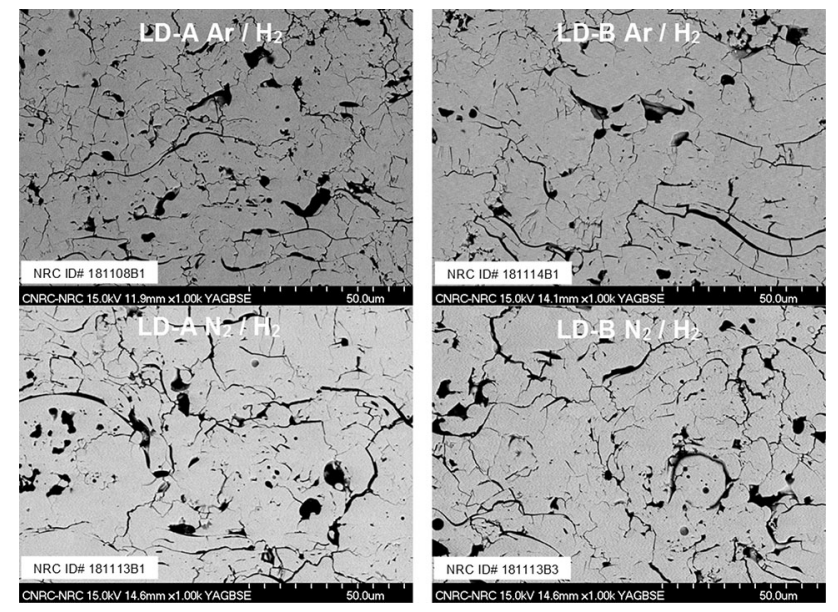

Fig. 3 SEM images $(\times 1000$ magnification) of the cross sections of the overall LD-A and LD-B YSZ topcoats sprayed using $\mathrm{Ar} / \mathrm{H}_{2}$ and $\mathrm{N}_{2} / \mathrm{H}_{2}$ plasmas

\section{Thermal Conductivity Measurements}

The TC values were measured for as-sprayed and heattreated $\left(1200{ }^{\circ} \mathrm{C}-10 \mathrm{~h}\right)$ samples, as shown in Fig. 4. The values for our industrial reference are also shown for comparison and in general are slightly lower than the ones of the samples prepared with the $9 \mathrm{MB}$ torch, in both assprayed and HT conditions. It should be noted, however, that the reference coating has a higher porosity level, in the range $15-18 \%$ in comparison with $11-13 \%$ for the $9 \mathrm{MB}$ coatings. This may account for the lower measured thermal conductivity of this coating. All coatings display an assprayed thermal conductivity in the range of $\sim 0.7-1.0$ $\mathrm{W} / \mathrm{mK}$ at RT (Fig. 4a), which is lower than fully dense monolithic YSZ (typically $2 \mathrm{~W} / \mathrm{mK}$ (Ref 2)), as a result of the presence of pores and microcracks in a direction that is perpendicular to the heat flux. According to Kulkarni et al. (Ref 11), the TC values of porous (8-15\%) as-sprayed YSZ TBCs deposited via the legacy 3MB Metco APS torch (Ar$\mathrm{H}_{2}$ plasma) are found within the range of $\sim 0.6-1.0 \mathrm{~W} / \mathrm{mK}$ at RT. Lima et al. (Ref 6) reported that the as-sprayed RT TC values of porous (13-22\%) YSZ sprayed via Ar- $\mathrm{H}_{2}$ and $\mathrm{N}_{2}-\mathrm{H}_{2}$ plasmas (legacy 3MB Metco APS torch) are in the range of $\sim 0.7-1.0 \mathrm{~W} / \mathrm{mK}$. Moreover, Tan et al. (Ref 12) have also shown that porous (10-13\%) YSZ TBCs sprayed using a $\mathrm{N}_{2}-\mathrm{H}_{2}$ plasma (legacy $7 \mathrm{MB}$ Metco APS torch) can also exhibit as-sprayed TC values within the $\sim 0.6-1.0$ $\mathrm{W} / \mathrm{mK}$ range. Consequently, the as-sprayed TC values at RT reported in this work are within these ranges and are considered to representative of porous APS YSZ TBCs.

After heat treatment and due to sintering, the TC at RT values is increased to $\sim 1.2-1.5 \mathrm{~W} / \mathrm{mK}$ (Fig. 4b). Lima et al. (Ref 6) observed an increase to $\sim 1.1-1.4 \mathrm{~W} / \mathrm{mK}$ at RT after the same heat treatment $\left(1200^{\circ} \mathrm{C}-10 \mathrm{~h}\right)$. It is interesting to observe that for both as-sprayed and heattreated YSZ TBCs, on average the lowest TC values from RT to $1200^{\circ} \mathrm{C}$ were given by the $\mathrm{N}_{2}$-based LD-B YSZ TBCs (Fig. 4).

Heat transfer occurs via conduction, radiation and convection, although convection is considered to be minor for APS TBCs. For both TBCs, from RT to $800^{\circ} \mathrm{C}$, their

Table 4 Results of the bond strength testing (ASTM C633)

\begin{tabular}{lccccl}
\hline NRC ID\# & Powder & Plasma gas & APS YSZ thickness $(\mu \mathrm{m})$ & Adhesion strength $(\mathrm{MPa})$ & \multicolumn{1}{c}{ Failure location } \\
\hline $181108 \mathrm{~B} 1$ & LD-A & $\mathrm{Ar} / \mathrm{H}_{2}$ & $\sim 424$ & $14 \pm 1(n=5)$ & Mixed failure-mostly within the BC (cohesive) \\
$181114 \mathrm{~B} 1$ & LD-B & $\mathrm{Ar} / \mathrm{H}_{2}$ & $\sim 431$ & $13 \pm 1(n=5)$ & Mixed failure-mostly within the BC (cohesive) \\
$181113 \mathrm{~B} 1$ & LD-A & $\mathrm{N}_{2} / \mathrm{H}_{2}$ & $\sim 428$ & $14 \pm 1(n=5)$ & Mixed failure-mostly within the BC (cohesive) \\
$181113 \mathrm{~B} 3$ & LD-B & $\mathrm{N}_{2} / \mathrm{H}_{2}$ & $\sim 432$ & $15 \pm 1(n=5)$ & Mixed failure-mostly within the BC (cohesive) \\
\multicolumn{1}{l}{\begin{tabular}{l} 
Dummy steel sample \\
\hline
\end{tabular}} & & $95(n=1)$ & Glue failure
\end{tabular}



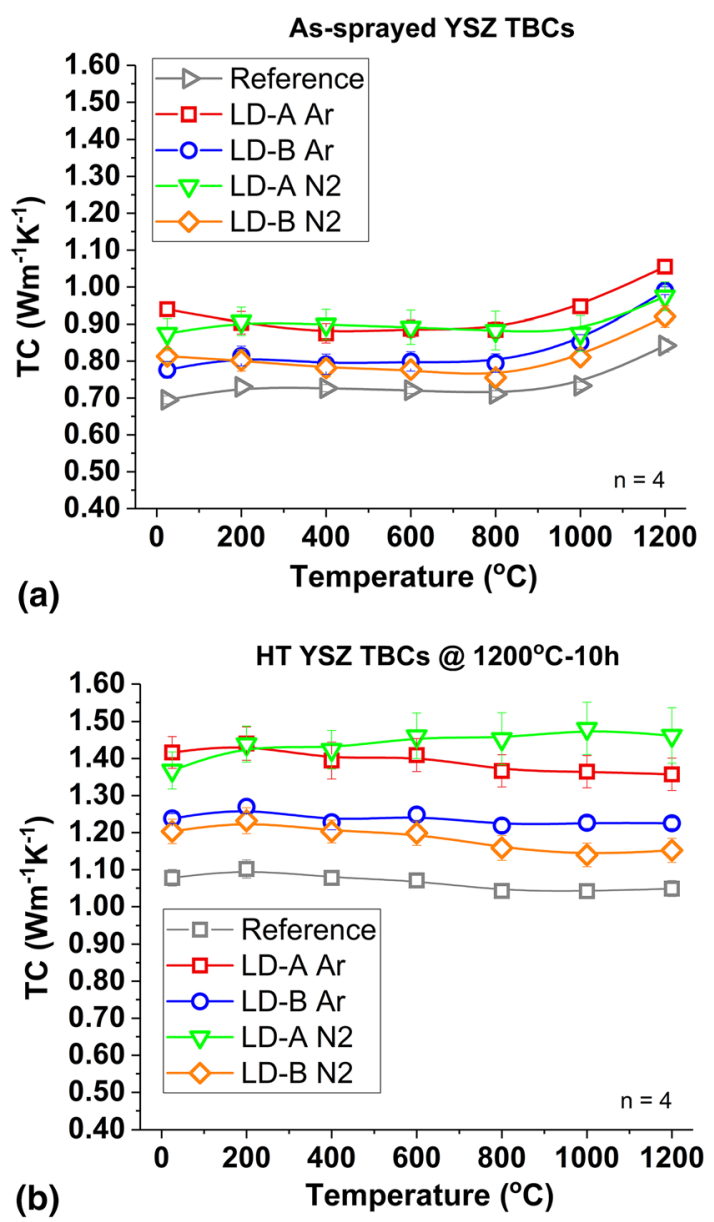

Fig. 4 Thermal conductivity (TC) of (a) as-sprayed and (b) heattreated $\left(1200{ }^{\circ} \mathrm{C}-10 \mathrm{~h}\right) \mathrm{YSZ}$ TBCs.

respective TC values remain nearly constant. However, after $800^{\circ} \mathrm{C}$, the TC values of the as-sprayed TBC begin to increase (Fig. 4a), whereas those of the heat-treated TBC (Fig. 4b) continue their near-linear trend.

To understand these distinct trends, one needs to realize that the heat treatment at $1200^{\circ} \mathrm{C}$ for $10 \mathrm{~h}$ that was performed before TC measurements had the objective to cause an initial sintering of the samples. It also guarantees that the YSZ microstructures would remain nearly stable prior to $\mathrm{TC}$ measurements at high temperatures (i.e., $1200^{\circ} \mathrm{C}$ ). Therefore, at $800^{\circ} \mathrm{C}$ and higher temperatures, the TC values for the heat-treated TBCs remain nearly constant.

On the contrary, for the as-sprayed YSZ TBCs, as they were not heat-treated prior to TC measurement, it is hypothesized that stress release (e.g., splat micro-sliding leading to an improved splat-to-splat contact) and perhaps an onset of sintering began at temperatures between 800 and $1200^{\circ} \mathrm{C}$ during the measurement. For these reasons, it is believed that the heat flux through the samples was boosted, thereby leading to an increase of TC values from $800-1200^{\circ} \mathrm{C}$ (Fig. 4a).
Despite the fact that all coatings have initially the same level of $\sim 1-20 \mu \mathrm{m}$ coarse porosity $(\sim 11-13 \%-$ Table 3 ), there are large differences in thermal conductivity and the degree of increase after sintering. The greatest increase in thermal conductivity relative to its as produced state is in the LD-A TBCs, produced both using Ar- and $\mathrm{N}_{2}$-based plasmas (Fig. 4b). This may be understood from both the powder and parameter perspective. LD-A powder exhibits a wider distribution of powder particle sizes (from 24 to $87 \mu \mathrm{m}$ ), while LD-B powder is slightly narrower (from 33 to $89 \mu \mathrm{m}$ ). The broader distribution of powder particles can lead to a larger difference in powder treatment in the plasma jet and consequential difference in deposition conditions for the YSZ material. It can be expected then that the LD-A powder with its broad distribution would result in a larger variation in powder/particle deposition conditions. Variations such as these may incorporate more semi-molten material in the final coating that shows higher degree of sintering at high temperatures for LD-A TBCs, as shown in Fig. 4(b).

Nonetheless, it is important to highlight again that the $\mathrm{N}_{2}$-based LD-B YSZ TBCs display the lowest TC values of all samples tested, even though their as-sprayed coarse porosity values $(\sim 1-20 \mu \mathrm{m})$ were similar (Table 3 ). Consequently, at this moment there are no concrete explanations about the trend of the $\mathrm{N}_{2}$-based LD-B YSZ TBCs to exhibit lower TC values than those of the other TBCs. However, besides coarse porosity, another factor is important when establishing TC in APS ceramic coatings. McPherson (Ref 13) pointed out that the true area of contact between two adjacent ceramic APS splats is about $20 \%$, whereas the remaining $80 \%$ of the contact area is characterized by planar gaps of about $100 \mathrm{~nm}$ in thickness. Moreover, McPherson (Ref 14) teaches why ceramic APS coatings typically exhibit lower TC values than those of bulk materials, even when both exhibit similar levels of coarse porosity $(\sim 1-20 \mu \mathrm{m}$ pore size). This "discrepancy" can be explained in terms of a model not only involving the coarse porosity but also involving the limited regions of contact between splats (i.e., 100-nm-thick planar gaps), which further reduce TC of APS coatings (Ref 14). Therefore, it is hypothesized that the spray conditions generated by the $\mathrm{N}_{2} / \mathrm{H}_{2}$ plasma and the LD-B powder are maximizing the presence of the planar intersplat gaps for the LD-B YSZ TBCs, thereby generating their tendency to exhibit lower TC values.

Finally, Xie et al. (Ref 15) reported that APS YSZ TBCs produced from YSZ feedstocks with different impurity levels (e.g., $\mathrm{SiO}_{2}, \mathrm{Al}_{2} \mathrm{O}_{3}, \mathrm{TiO}_{2}$ and $\mathrm{Fe}_{2} \mathrm{O}_{3}$ ) can exhibit significant different sintering rates. Briefly, the higher the amount of impurities, the higher the YSZ TBC sintering. Considering the fact that both powders exhibited the same chemical composition (Table 1), the differences observed 
in TC values, mostly for the heat-treated samples, cannot be related to different impurity levels.

\section{Thermal Cycle Life: furnace cycle testing (FCT)}

The performance of coatings in FCT was evaluated and compared to an industrial reference. The coatings prepared in this work and the industrial reference displayed similar porosities (11-13\% and 15-18\%, respectively). The corresponding cycle lifetime results are shown in Fig. 5. It is evident that the two $\mathrm{N}_{2}$-based TBCs exhibited the best FCT performance, outmatching the industrial reference TBC and both Ar-based TBCs. It needs to be pointed out again that the PFRs and DE values of the $\mathrm{N}_{2}$-based TBCs were $50 \%$ and 35\% higher than those of the Ar-based TBCs. Consequently, this is an important achievement. This outcome supports the results obtained in the previous study (Ref 6), which showed that nitrogen-plasma TBCs could perform as well as argon plasma-based TBCs in FCT evaluation.

It is beyond the scope of this work to analyze in detail these FCT results. However, some evaluation is necessary. Initially, it needs to be reminded that all YSZ TBCs were sprayed over the same type of substrate and BC. Shinoda et al. (Ref 16) demonstrated the evolving stresses during APS spraying of YSZ increase with the DR and deposition temperature (with the powder feed rate or with the inverse of the robot-scanning speed). Moreover, it is stated that DR can be increase up to a limit, where vertical cracks as well as branching cracks can be induced, thereby resulting in lowering of the evolving stress, which was not observed in this current work. Consequently, higher DRs and deposition temperatures will induce higher residual stress levels in thermally spray coatings, thereby probably contributing to distinct coating performance when subjected to stress/

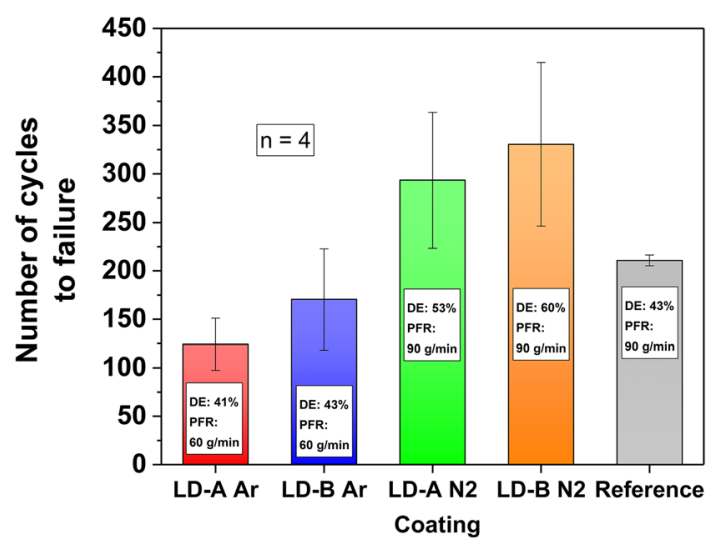

Fig. 5 Number of cycles to failure in the furnace cycle testing for the different coatings and an industrial reference. For each type of coating, the average for four tested samples is given, along with the standard deviation. strain. Based on Table 3, the average DR and deposition temperatures for the Ar- and $\mathrm{N}_{2}$-based YSZ TBCs were $\sim 27$ and $\sim 41 \mu \mathrm{m} /$ pass and $\sim 150$ and $\sim 200^{\circ} \mathrm{C}$, respectively. Consequently, the higher DRs and deposition temperature (i.e., residual stress) for the $\mathrm{N}_{2} / \mathrm{H}_{2}$ TBCs do not seem to have caused any negative effect on the FCT results, as they exhibited superior FCT performance. The same concept can be applied to the bond strength results (Table 4). The different DRs and deposition temperatures did not influence the TBC adhesion on the bond-coated substrate. As all TBCs displayed similar as-sprayed adhesion values including the reference sample $(\sim 17 \mathrm{MPa}$ expected adhesion as previously published (Ref 17)), so this parameter was also not predictive of the behavior in thermal cycle testing, as the coatings failed at different lifetimes.

Micrographs of the samples after FCT are shown in Fig. 6. In all cases, the thermally grown oxide (TGO) on the $\mathrm{BC}$ is evident. The presence of horizontal cracks at the interface of the topcoat with the bond coat is also visible. As pointed out by Padture et al. (Ref 1), the horizontally oriented microcracking typically propagates within (1) the boundaries of YSZ/TGO/BC interfacial zones or (2) within the YSZ topcoat but adjacent to the TGO. All these spallation modes develop simultaneously with the high oxidation of the BC. It can be seen that the TBC failure for the Ar-based TBCs was mostly found within the edges of YSZ/ TGO/BC interfacial zones, whereas that of the $\mathrm{N}_{2}$-based TBCs predominantly occured within the YSZ topcoat but adjacent to the TGO (Fig. 6). As previously mentioned, the average DRs for the Ar- and $\mathrm{N}_{2}$-based YSZ TBCs were $\sim 27$ and $\sim 41 \mu \mathrm{m} /$ pass, respectively (Table 3). Consequently, the higher DRs (i.e., residual stress) of the $\mathrm{N}_{2}$ based TBCs probably contributed to yield their distinct spallation mode and vice versa.
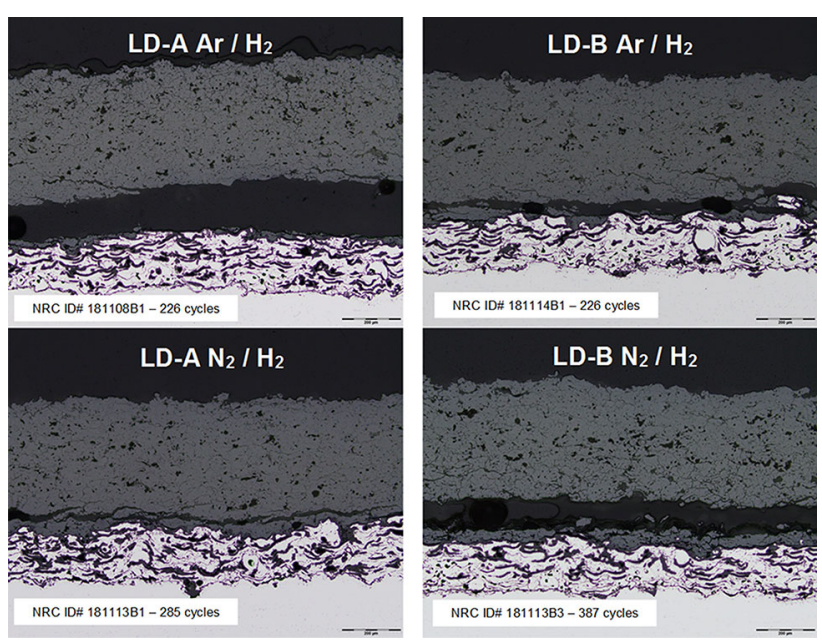

Fig. 6 Micrographs of the coatings after FCT testing. 
As formerly stated, Lima et al. (Ref 6) reported that nitrogen-plasma TBCs could perform as well as argonplasma based TBCs in FCT evaluation. In a similar way to this study, the $\mathrm{Ar} / \mathrm{H}_{2}$ TBCs also failed within the YSZ/ $\mathrm{TGO} / \mathrm{BC}$ interfacial zones, while the $\mathrm{N}_{2} / \mathrm{H}_{2}$ TBCs likewise failed within the YSZ layer, right above the TGO interface. In that paper, these distinct mechanisms of failure were associated with differences in residual stress levels, as the DR values for nitrogen-plasma TBCs were $\sim 50 \%$ higher than those of the argon-plasma TBCs (Ref 6). Consequently, the residual stresses are likely playing a role in the spallation location of the TBCs. However, according to "conventional wisdom," higher residual stress levels would induce "low" TBC FCT performance. Notwithstanding, this event (i.e., hindering of FCT performance due to higher residual stresses) was not observed in the present work, as well as, by Lima et al. (Ref 6). Of course, in both works the thicknesses of all APS YSZ TBCs were within the same range $(\sim 400-500 \mu \mathrm{m})$.

As already highlighted, APS YSZ TBCs produced from YSZ feedstocks with different impurity levels can exhibit significant different sintering rates (Ref 15). Higher sintering rates translate into higher TBC stiffening, leading to lower thermal cycle capabilities. Nonetheless, as both feedstocks exhibit the same composition (Table 1), this issue cannot not applicable in trying to understand the current FCT results.

Nonetheless, it is interesting to compare the rankings of TC values for the heat-treated samples (Fig. $4 \mathrm{~b}$ ) and FCT performance (Fig. 5). Firstly, the $\mathrm{N}_{2}$-based LD-B TBCs outperformed the other TBCs in terms of exhibiting the lowest TC values after heat treatment and the maximum FCT endurance. Therefore, it is hypothesized that the $\mathrm{N}_{2^{-}}$ based LD-B TBCs are displaying the lowest sintering/densification rates among all the TBCs manufactured and tested in this study. The trend of lower sintering/densification (i.e., stiffening) of the $\mathrm{N}_{2}$-based LD-B TBCs at high temperatures would translate into lower growth of TC values and enhanced thermal cycle lives when compared to those of the other TBCs, which were observed in this work. Still, further investigations are required to better understand the differences in TBC failure between the nitrogen and argon-based plasma coatings.

Finally, in a "simplistic way," it can be stated that FCT evaluates the ability of the ceramic TBC to resist (1) the stresses of the thermal cycle, as well as (2) the stresses generated by the thickening of the TGO layer. As in this work the same type of bond coat and substrate were employed, any differences in performance can only be attributed the topcoat properties. For this reason, it is hypothesized that (1) the use of $\mathrm{N}_{2}$ as primary plasma gas and (2) the optimized set of $\mathrm{N}_{2} / \mathrm{H}_{2}$ spray parameters employed in this study had a decisive impact regarding the superior performance of the $\mathrm{N}_{2}$-based YSZ LD-B TBC that was observed in FCT.

\section{Conclusions}

Two YSZ feedstocks (LD-A and LD-B), exhibiting the same composition and morphology but distinct granulometries, were employed in this study. The YSZ TBCs were prepared with $\mathrm{Ar} / \mathrm{H}_{2}$ and $\mathrm{N}_{2} / \mathrm{H}_{2}$ plasmas using a legacy APS torch (Metco 9MB) at powder feed rates of 60 and $90 \mathrm{~g} / \mathrm{min}$, respectively. In spite of the higher powder feed rate, the $\mathrm{N}_{2}$-based plasma yielded higher deposition efficiency values (average 57\%) than those of the Ar one (average 41\%). The coatings displayed similar microstructures, adhesion strength (13-15 MPa) and porosity levels (11-13\%). However, the $\mathrm{N}_{2} / \mathrm{H}_{2}$ LD-B TBCs exhibited the lowest thermal conductivity values and highest lifetime in FCT evaluation. In this particular case, the nature of the processing gas clearly has an effect on the coating performance. The key factors necessary to explain the results were not yet identified and require further study. However, it is hypothesized that the $\mathrm{N}_{2} / \mathrm{H}_{2} \mathrm{LD}-\mathrm{B} \mathrm{TBC}$ is exhibiting the lowest sintering/densification rates at high temperatures; thus, the its optimal performance. Nonetheless, it is important to point out that the current results on the use of a nitrogen-based plasma corroborate to what was reported in previous work (Ref 6). Both studies show the potential of $\mathrm{N}_{2}$ to replace $\mathrm{Ar}$ as the primary plasma gas in legacy APS torches (e.g., Metco $3 \mathrm{MB}$ and 9MB) for industrial applications, toward bringing down production costs without compromising TBC quality.

Acknowledgments The authors would like to acknowledge the contribution of the Thermal Spray team technical officers at NRC Boucherville: Jean-Claude Tremblay (coatings preparation), David de Lagrave (metallographic preparation and optical microscope images), Caroline Hoang (powder characterization) and Karine Théberge (SEM images).

\section{References}

1. N.P. Padture, M. Gell and E.H. Jordan, Thermal Barrier Coatings for Gas-Turbine Engine Applications, Science, 2002, 296(5566), p 280-284.

2. A. Feuerstein, J. Knapp, T. Taylor, A. Ashary, A. Bolcavage and N. Hitchman, Technical and Economical Aspects of Current Thermal Barrier Coating Systems for Gas Turbine Engines by Thermal Spray and EBPVD: A Review, J. Therm. Spray Technol., 2008, 17(2), p 199-213.

3. H. Ingham and F. Aj, Comparison of Plasma Flame Spray Gases, Weld. J., 1975, 10(10), p 101-105.

4. A.B. Murphy and C. Arundelli, Transport Coefficients of Argon, Nitrogen, Oxygen, Argon-Nitrogen, and Argon-Oxygen Plasmas, Plasma Chem. Plasma Process., 1994, 14(4), p 451-490. 
5. B.R. Marple, R.S. Lima, C. Moreau, S.E. Kruger, L. Xie and M. Dorfman, Yttria-Stabilized Zirconia Thermal Barriers Sprayed Using $\mathrm{N}_{2}-\mathrm{H}_{2}$ and $\mathrm{Ar}-\mathrm{H}_{2}$ Plasmas: Influence of Processing and Heat Treatment on Coating Properties, J. Therm. Spray Technol., 2007, 16(5-6), p 791-797.

6. R.S. Lima, B.M. Guerreiro, N. Curry, M. Leitner and K. Körner, Environmental, Economical, and Performance Impacts of Ar- $\mathrm{H}_{2}$ and $\mathrm{N}_{2}-\mathrm{H}_{2}$ Plasma-Sprayed YSZ TBCs, J. Therm. Spray Technol., 2020, 29(1-2), p 74-89.

7. G. Di Girolamo, C. Blasi, L. Pagnotta and M. Schioppa, Phase Evolution and Thermophysical Properties of Plasma Sprayed Thick Zirconia Coatings After Annealing, Ceram. Int., 2010, 36(8), p 2273-2280.

8. R. Kromer, J. Cormier and S. Costil, Role of Powder Granulometry and Substrate Topography in Adhesion Strength of Thermal Spray Coatings, J. Therm. Spray Technol., 2016, 25(5), p 933-945.

9. R. Ghasemi and H. Vakilifard, Plasma-Sprayed Nanostructured YSZ Thermal Barrier Coatings: Thermal Insulation Capability and Adhesion Strength, Ceram. Int., 2017, 43(12), p 8556-8563.

10. J. Smith, J. Scheibel, D. Classen, S. Paschke, S. Elbel, K. Fick and D. Carlson, Thermal Barrier Coating Validation Testing for Industrial Gas Turbine Combustion Hardware, J. Eng. Gas Turbines Power, 2016, 138(3), p 215-220.

11. A. Kulkarni, Z. Wang, T. Nakamura, S. Sampath, A. Goland, H. Herman, J. Allen, J. Ilavsky, G. Long and J. Frahm, Comprehensive Microstructural Characterization and Predictive Property
Modeling of Plasma-Sprayed Zirconia Coatings, Acta Mater., 2003, 51(9), p 2457-2475.

12. Y. Tan, J.P. Longtin, S. Sampath and H. Wang, Effect of the Starting Microstructure on the Thermal Properties of As-sprayed and Thermally Exposed Plasma-Sprayed YSZ Coatings, J. Am. Ceram. Soc., 2009, 92(3), p 710-716.

13. R. McPherson, A Review of Microstructure and Properties of Plasma Sprayed Ceramic Coatings, Surf. Coat. Technol., 1989, 39, $\mathrm{p} \mathrm{173-181.}$

14. R. McPherson, A Model for the Thermal Conductivity of PlasmaSprayed Ceramic Coatings, Thin Solid Films, 1984, 112(1), p 8995.

15. L. Xie, M. Dorfman, A. Cipitria, S. Paul, I. Golosnoy and T. Clyne, Properties and Performance of High-Purity Thermal Barrier Coatings, J. Therm. Spray Technol., 2007, 16(5-6), p 804808.

16. K. Shinoda, J. Colmenares-Angulo, A. Valarezo and S. Sampath, Effect of Deposition Rate on the Stress Evolution of PlasmaSprayed Yttria-Stabilized Zirconia, J. Therm. Spray Technol., 2012, 21(6), p 1224-1233.

17. N. Markocsan, P. Nylén, J. Wigren, X.-H. Li and A. Tricoire, Effect of Thermal Aging on Microstructure and Functional Properties of Zirconia-Base Thermal Barrier Coatings, J. Therm. Spray Technol., 2009, 18(2), p 201-208.

Publisher's Note Springer Nature remains neutral with regard to jurisdictional claims in published maps and institutional affiliations. 